\title{
Kolaborasi Pemasaran Digital Menggunakan Media Sosial dan Marketplace untuk Meningkatkan Produktivitas UMKM
}

\author{
Fetty Tri Anggraeny, Dedin F. Rosida, \\ Wahyu S.J. Saputra, Handoyo Prasetyo \\ UPN "Veteran" Jawa Timur \\ fettyanggraeny.if@upnjatim.ac.id, rosy.upnsby@gmail.com, \\ wahyu.s.j.saputra@gmail.com, handoyoprasetyo@upnvj.ac.id
}

\begin{abstract}
Digital marketing is currently growing rapidly. The COVID-19 pandemic has increasingly triggered the acceleration of digital marketing, especially for SME (Small and Medium Entreprise). The growth of social media users and marketplace users both as buyers and sellers has also soared. Today's society is starting to shift to cashless transactions. Both social media and marketplace have advantages that can be collaborated as digital marketing. Social media with diverse users and a marketplace that offers easy online store management and promo programs. The collaboration of these 2 digital tools is able to increase the productivity of UMKM.
\end{abstract}

Keywords: Digital Marketing, Healthy Snack, UMKM, Marketplace, Social Media

\section{Pendahuluan}

Persaingan Global merupakan suatu tahapan perkembangan fenomena budaya yang mau tak mau harus dilalui oleh perjalanan peradaban maupun sendi-sendi kehidupan manusia. Yang penting adalah, bagaimana menyikapi dan mempersiapkan diri menyongsong datangnya fenomena tersebut. Negara-negara di Eropa dalam menyikapi pasar global yaitu dengan menumbuhkembangkan dan meningkatkan kelompok usaha kecil dan menengah. Kebijakan untuk lebih memusatkan arah pandangan ke usaha kecil dan menengah (UKM) telah menjadi kecenderungan waktu itu, di mana semakin banyaknya dan meratanya peranan UKM tersebut, maka dinamika perekonomian akan lebih cepat meningkatkan kesejahteraan masyarakat luas dengan lebih merata.

UMKM merupakan Usaha yang disebut dengan usaha emas. Hal ini dibuktikan pada saat krisis moneter, UMKM mampu bertahan dan berkembang. Dengan demikian, perusahaanperusahaan diseluruh dunia ditantang untuk menjadi lebih bersaing secara strategis dalam pasar domestic mereka. Bagaimanapun, karena patokan untuk bersaing secara strategis berhubungan dengan standard global, perusahaan yang meningkatkan kemampuan untuk persaingan domestic secara bersamaan ikut pula meningkatkan daya bersaing global mereka.

Pemasaran online adalah praktik memanfaatkan saluran berbasis web untuk menyebarkan pesan tentang merek, produk, atau layanan perusahaan kepada calon pelanggannya. Metode dan teknik yang digunakan untuk pemasaran online termasuk email, media sosial,

Published by:

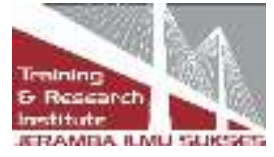


periklanan tampilan, optimisasi mesin pencari, dan banyak lagi. Tujuan pemasaran adalah untuk menjangkau calon pelanggan melalui saluran di mana mereka menghabiskan waktu untuk membaca, mencari, berbelanja, atau bersosialisasi secara online. Program Kementrian Kominfo sejak tahun 2016, UMKM Go Online, dimana memiliki target 8 juta UMKM pada tahun 2019. Program UMKM Go Online berupaya membantu masyarakat kecil terutama pengusaha mikro, kecil dan menengah untuk ikut berjualan daring dengan memanfaatkan marketplace yang tersedia, seperti Bukalapak, Tokopedia, Shopee, OLX dan lain-lain. Dari total 62,9 juta UMKM nasional, sebanyak 17.113.220 UMKM telah onboarding ke marketplace. Angka ini sudah sangat jauh melebihi target Kominfo pada tahun 2019 bahkan sudah lebih dari 2 kali lipat dari target 2019. UMKM harus serius dalam pengembangan bisnisnya secara online, agar produk yang ditawarkan dapat menjangkau pasar konsumen yang lebih luas, baik dalam negeri bahkan luar negeri.

UD. Rinjani Cookies sebagai salah satu UMKM skala rumah tangga telah menghasilkan beberapa cake dan cookies yang lebih sehat dengan penggunaan bahan-bahan non-terigu (gluten-free), lemak sehat (minyak kelapa) dan gula serta susu dengan Indeks Glikemik (Ig) rendah. Camilan sehat yang sudah diproduksi adalah cake brownies, cake lapis Surabaya dan cookies coklat dengan menggunakan tepung gluten-free dari umbi kimpul. Cake memiliki masa simpan yang singkat dibandingkan cookies, sehingga ini menjadi tantangan tersendiri bagi mitra. Saat ini banyak beredar makanan yang sebelumnya berbentuk cake diubah menjadi bentuk cookies crispy. Harapannya mitra dapat menghadirkan camilan sehat serta yang dapat diterima oleh pangsa pasar dengan range usia lebih lebar.

Pelanggan produk-produk UD. Rinjani Cookies masih di lingkungan rumah ataupun pertemanan dan masih sedikit menarik minat konsumen, beberapa faktor yang menjadi penyebab antara lain:

a. Metode marketing

UD. Rinjani Cookies saat ini menggunakan promosi melalui media whatsapp dan belum memaksimalkan toko online di marketplace. Sehingga range area konsumen masih sangat sempit, yaitu konsumen yang dekat dengan pemilik ataupun konsumen yang mendapat berita mulut ke mulut mengenai produk UD. Rinjani Cookies.

\section{b. Desain kemasan}

Desain kemasan yang digunakan UD. Rinjani Cookies merupakan kemasan sederhana, yaitu toples kue lebaran untuk kukis dan mika brownies untuk cake brownies dan lapis Surabaya, yang kemudian ditempel dengan stiker. Salah satu kelemahan dari kemasan yang digunakan adalah menyulitkan ketika harus dibawa dalam perjalanan.

\section{c. Bahan promosi}

UD. Rinjani Cookies mengambil foto produk dengan teknik sederhana dan langsung dijadikan sebagai bahan promosi. Yang mengakibatnya foto produk kurang menarik dan tidak adanya keterangan dari produk. Sedangkan bahan promosi online sangat mengandalkan desain dan foto produk yang apik sehingga dapat menarik minat pembeli.

d. Bentuk produk

Tidak dapat dipungkiri, kekuatan permintaan pasar merupakan salah satu faktor stabilitas

Published by:

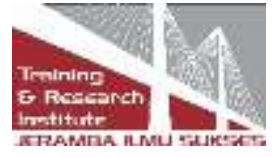


usaha. Berjamurnya makanan/minuman kekinian tidak lepas dari permintaan pasar yang semakin tinggi. Bentuk produk camilan sehat UD. Rinjani merupakan produk yang sudah umum dan tidak kekinian, sehingga sulit untuk menarik minat pembeli. Selain itu produk jenis cake memiliki masa simpan yang singkat sehingga harus dibuat fresh ketika ada permintaan.

\section{Solusi Masalah}

UD. Rinjani Cookies harus segera melakukan transformasi marketing sehingga usahanya akan memiliki produktivitas yang sehat. Peralihan menjadi marketing online perlu adanya beberapa persiapan pendukung selain mempersiapkan media promosi, yaitu antara lain pemilihan kemasan dan label yang baik dan pengambilan foto produk. Marketing online yang akan digunakan adalah mengkolaborasikan 2 software yang saling melengkapi dengan fitur-fitur yang mendukung kebutuhan UMKM. Kedua software tersebut adalah media sosial dan pasar digital (marketplace).

\subsection{Perkembangan metode pemasaran}

Metode pemasaran dari tahun ke tahun mengalami perubahan yang signifikan. Dengan pesatnya kemajuan teknologi internet metode pemasaran yang sebelumnya konvensional mau tidak mau bergerak ke pemasaran online. Adapun perubahan metode pemasaran ditunjukkan pada Gambar 1. Era konvensional jual beli dilakukan di pasar (pasar, kios, mall) dan penjual harus memiliki ruang jualan dan pembeli datang ke penjual. Atau penjual harus keliling menjajakan jualannya untuk mendekat ke pembeli. Era handphone, menawarkan produk kepada teman yang tersimpan kontaknya di handphone. Era sosmed, menawarkan produk melalui media social (facebook, Instagram). Dengan memanfaatkan media social jejaring pertemanan lebih luas karena setiap akun maksimum 5000 pertemanan. Marketplace adalah website atau aplikasi yang berfungsi semacam pasar tempat bertemunya penjual dan pembeli, dilakukan di dunia maya (online). Pada dasarnya, pemilik marketplace tidak bertanggung jawab atas barang-barang yang dijual karena tugas mereka adalah menyediakan tempat bagi para penjual yang ingin berjualan dan membantu mereka untuk bertemu pelanggan dan melakukan transaksi dengan lebih simpel dan mudah. Transaksinya diatur oleh marketplacenya. Kemudian setelah menerima pembayaran, penjual akan mengirim barang ke pembeli. Salah satu alasan mengapa marketplace terkenal adalah karena kemudahan dan kenyamanan dalam penggunaan.

Published by: 


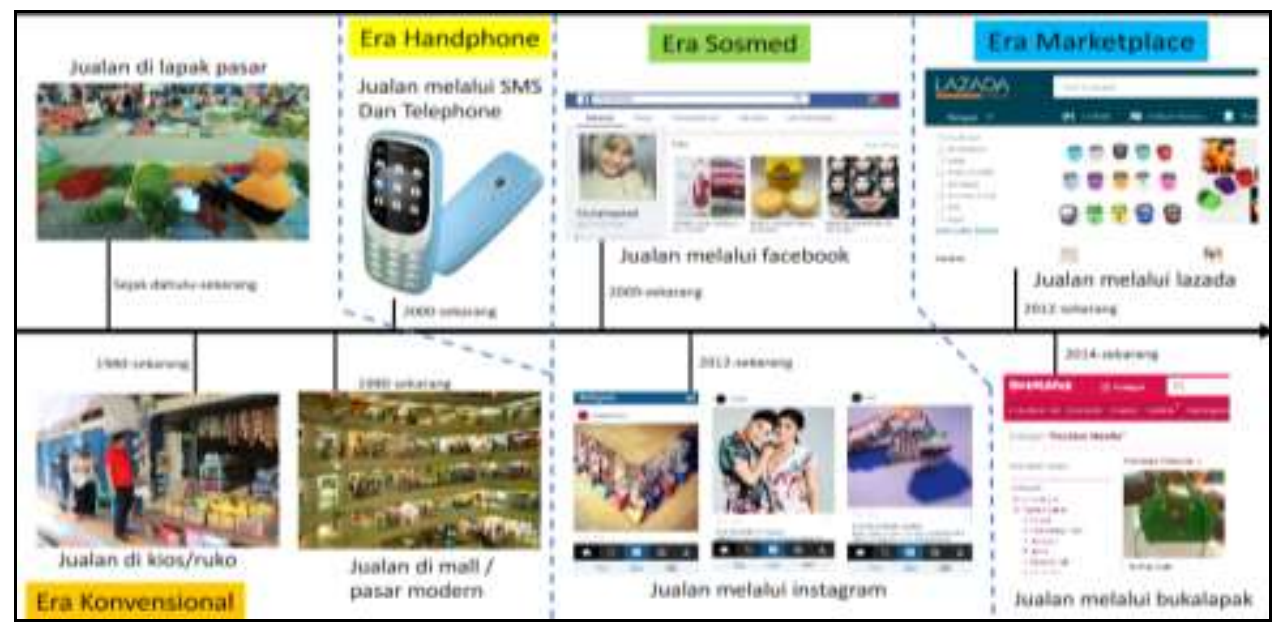

Gambar 1. Perkembangan metode pemasaran.

Jenis-jenis pemasaran online:

a. Pemasaran online dasar

Jenis pemasaran online ini menggunakan komputer/laptop dan handphone. Merupakan jenis pemasaran paling dasar karena menggunakan kontak telepon yang tersimpn di handphone

b. Pemasaran online menengah

Pemasaran online menengah menggunakan media social, seperti facebook, Instagram, whatsapp.

c. Pemasaran online lanjutan

Pemasaran online lanjutan, bergabung di marketplace seperti tokopedia, Lazada, shopee, dan sebagainya.

\subsection{Media Sosial}

Media sosial (sering disalahtuliskan sebagai sosial media) adalah sebuah media daring yang digunakan satu sama lain yang para penggunanya bisa dengan mudah berpartisipasi, berinteraksi, berbagi, dan menciptakan isi blog, jejaring sosial, wiki, forum dan dunia virtual tanpa dibatasi oleh ruang dan waktu (Wikipedia, 2021). Saat ini media sosial sangat berkembang, banyak aplikasi yang bermunculan menawarkan fitur yang unik. Kaplan dan Haenlein membagi media sosial menjadi 6 (enam) jenis yaitu proyek kolaborasi (Wikipedia), blog dan microblog (Twitter dan Facebook), konten (Instagram, TikTok, dan Youtube), situs jejaring sosial (Instagram dan Facebook), virtual game world dan virtual social world.

Hootsuite (We are social) sebagai salah satu situs layanan manajemen konten pada berbagai media sosial, secara berkala menyajikan data terkait bagaimana orang menggunakan internet, seluler, media sosial dan e-commerce. Berdasarkan data Hootsuite pada tahun 2020 dengan judul "Digital 2020 Indonesia: All The Data, Trends, And Insights You Need

Published by:

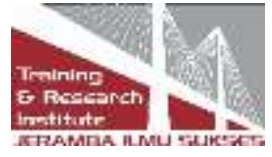


To Help You Understand How People Use The Internet, Mobile, Social Media, And Ecommerce", sebanyak 59\% (160 juta) dari populasi penduduk Indonesia (272,1 juta) menggunakan media sosial secara aktif (Hootsuite, 2020), Gambar 2a. Dan media sosial yang paling sering digunakan peringkat 3 teratas adalah youtube, whatsapp, dan facebook (Gambar 2b). Facebook diakses oleh 82\% (147,4 juta) penduduk Indonesia yang berusia 16-64 tahun (179,7 juta).

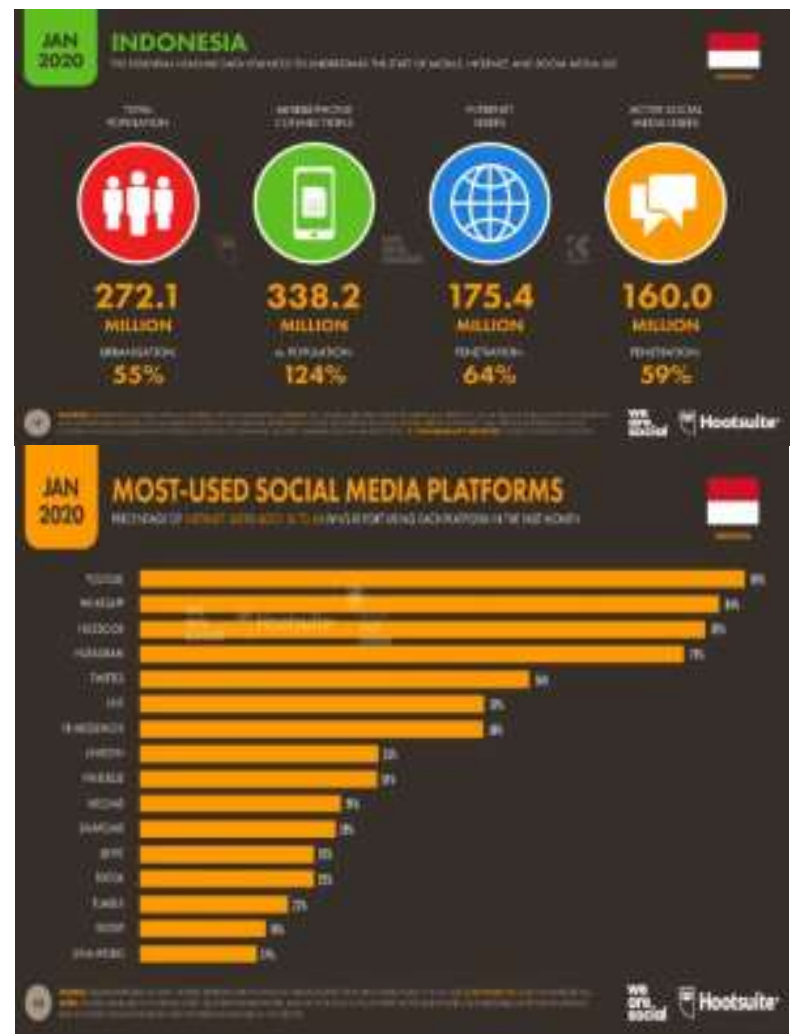

Gambar 2. (a) Pengguna internet dan (b) Rangking pengguna sosial media (Hootsuite, 2020).

Angka pengguna facebook di Indonesia bukanlah jumlah yang sedikit, ini merupakan jumlah yang cukup besar dan sangat sesuai sebagai target pasar produk UMKM. Sudah banyak sekali pengusaha baik kecil, menengah ataupun besar memanfaatkan media sosial untuk menjaring konsumen. Hootsuite juga mencatat bahwa ada sekitar 130 juta pengguna facebook yang dapat dijangkau dengan iklan (Gambar 3a). Sedangkankan pada media sosial Instagram, pengguna yang dapat dijangkau iklan masih sekitar 60 juta. Hal inilah yang memperkuat posisi facebook dibandingkan Instagram untuk dijadikan sebagai pasar dari produk-produk usaha (Gambar 3b).

Published by: 


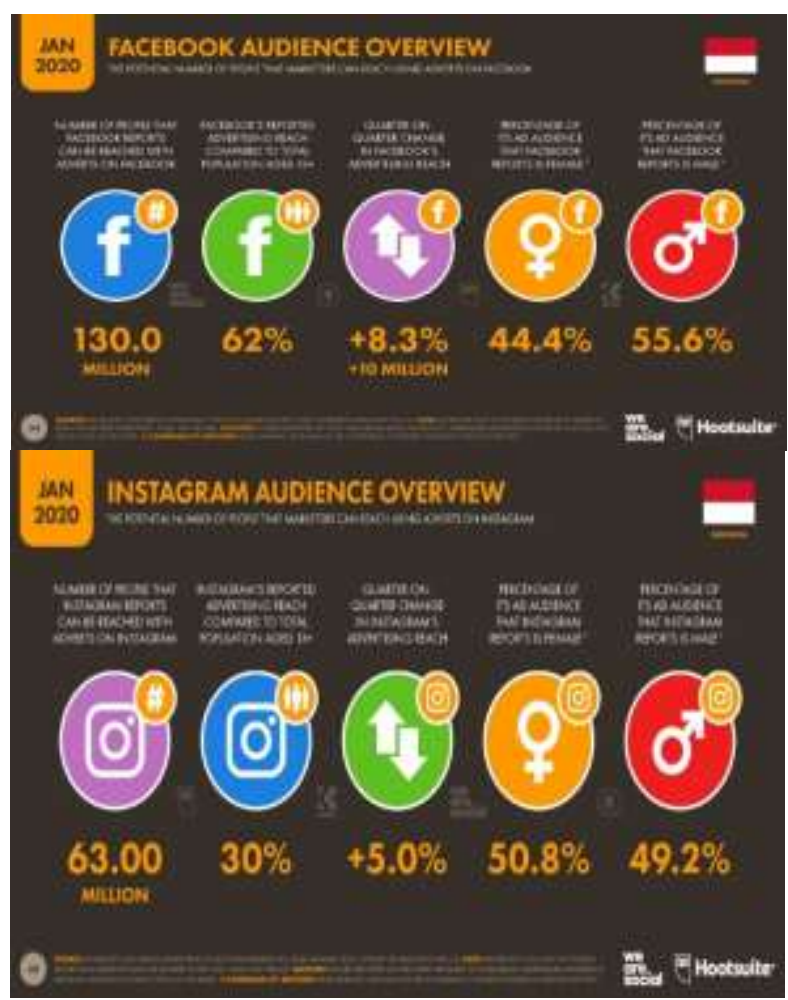

Gambar 3. Pengguna media sosial (a) facebook dan (b) Instagram (Hootsuite, 2020).

\subsection{Marketplace}

Gambar 1 menunjukkan bahwa saat ini kita berada di era metode pemasaran marketplace. Dimana marketplace adalah suatu media online yang mempertemukan penjual dan pembeli, dengan kata lain marketplace adalah pasar online. Contoh marketplace yang sering digunakan adalah Shopee, Tokopedia, Bukalapak.

Hasil pengumpulan data yang dilakukan oleh iprice insight menunjukkan bahwa pada kuartal 2 tahun 2021, marketplace Tokopedia menduduki peringkat pertama yang disusul dengan marketplace Shopee di peringkat 2 dan Bukalapak di peringkat 3 (Iprice Insight, 2021). Meskipun aplikasi tokopedia menduduki peringkat dibawah aplikasi Instagram baik di AppStore maupun PlayStore, hal ini menunjukkan bahwa masih banyak pengguna Tokopedia yang mengakses melalui website.

Published by: 


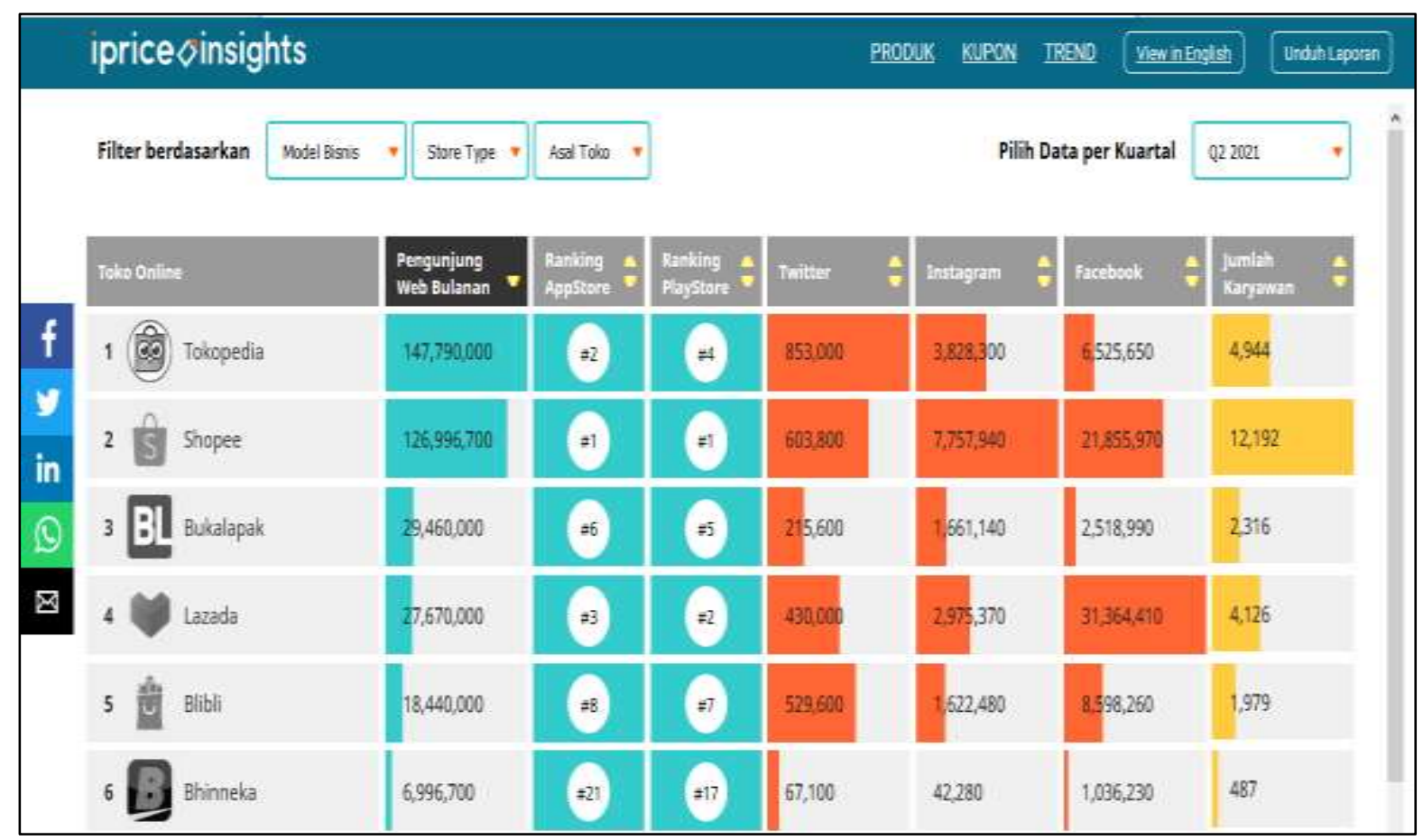

Gambar 4. Data rangking marketplace (Iprice Insight, 2021).

\section{Metode Pelaksanaan}

\subsection{Pelatihan Pemasaran Menggunakan Sosial Media}

Media sosial yang digunakan adalah Facebook. Ada 2 metode marketing yang bisa dilakukan di media sosial, organik dan anorganik. Marketing organik adalah marketing yang tidak menggunakan layanan iklan yang disediakan oleh media sosial, dengan kata lain marketing organic nol biaya. Sedangkan marketing anorganik adalah menggunakan layanan iklan yang disediakan oleh media sosial dan tentunya ada biaya yang harus dibayarkan. Marketing organic dilakukan dengan cara postingan blog, konten situs, postingan tamu, tweet, dan update status maupun story. Strategi ini tidak akan menghabiskan tagihan belanja, tetapi harus menginvestasikan waktu dan energi yang cukup banyak. Dengan demikian dapat terbentuk audiens dan basis penggemar produk yang ditawarkan. Pemasaran organic membawa pelanggan secara alami, sehingga bisnis yang memilih menggunakan strategi organic harus menyediakan Informasi yang dicari pelanggan. Tetapi karena berproses secara alami maka diperlukan waktu yang cukup lama, berbulan-bulan atau bahkan bertahun-tahun.

\subsection{Pelatihan Pemasaran Menggunakan Marketplace}

Selain menggunakan media sosial, UD. Rinjani Cookies juga dikenalkan pemasaran menggunakan marketplace. Dengan menggunakan marketplace banyak kemudahan yang didapat, antara lain histori order, pelacakan pengiriman dan pembayaran, sampai pada promo-promo yang ditawarkan untuk menarik minat pembeli.

Published by:

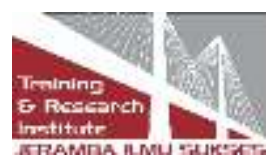




\subsection{Pelatihan pemilihan kemasan}

Desain kemasan yang digunakan UD. Rinjani Cookies merupakan kemasan sederhana, yaitu toples kue lebaran untuk kukis dan mika brownies untuk cake brownies dan lapis Surabaya, yang kemudian ditempel dengan stiker (Gambar 5). Salah satu kelemahan dari kemasan yang digunakan adalah menyulitkan ketika harus dibawa dalam perjalanan.

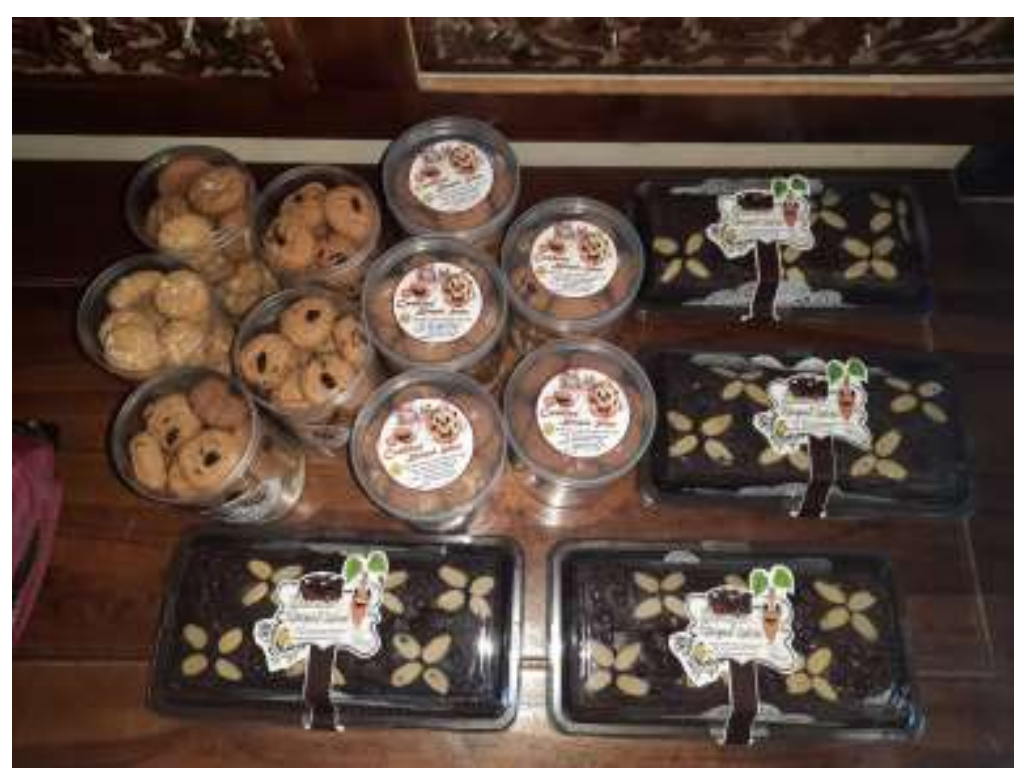

Gambar 5. Kemasan dan foto produk UD. Rinjani Cookies.

\section{Hasil Pelaksanaan dan Diskusi}

\subsection{Pelatihan marketplace}

Marketplace yang digunakan adalah shopee, semua produk yang dijual UD. Rinjani Cookies dimasukkan di daftar katalog produk. Adapun produk terdiri dari kue kering dan kue basah, kue basah antara lain cake dan bolu sedangkan kue kering camilan olahan tepung kimpul. Penjualan kue basah diatur dengan sistem PO (purchase order) agar produk yang dikirim adalah produk baru. Sedangkan kue kering disediakan stok karena memiliki daya simpan lebih lama dibandingkan kue basah.

Published by: 
Vol. 2 No. 2, Juli-Desember 2021

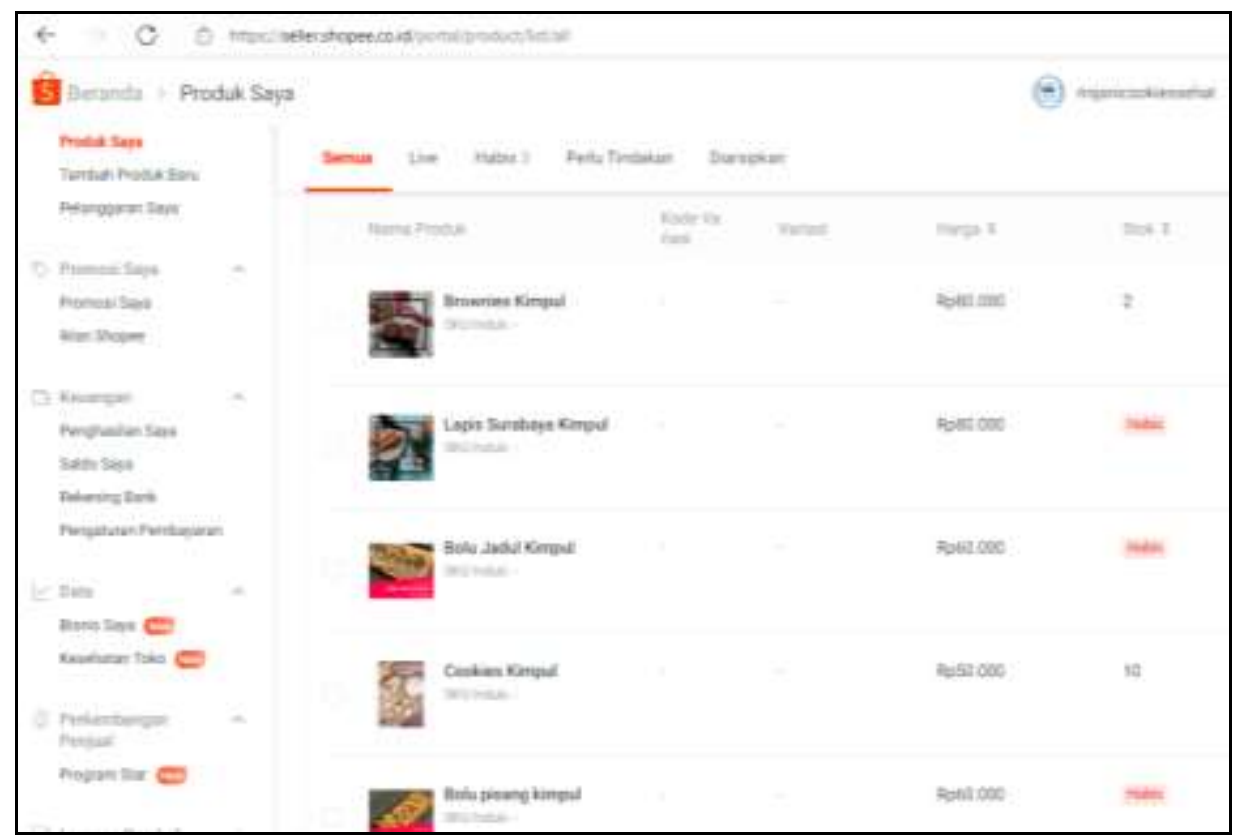

Gambar 5. Halaman toko online UD. Rinjani Cookies di Shopee.com

\subsection{Pelatihan media sosial}

Dalam hal ini selain dikenalkan metode marketing organic juga dikenalkan adanya marketing anorganik yaitu dengan menggunakan fbAds. Hasil dari pelatihan marketing organic, UMKM sudah dapat membuat akun facebook dan menambahkan halaman khusus untuk produk-produknya (Gambar 6). Pelatihan marketing anorganik dilaksanakan secara online dengan menghadirkan praktisi marketing online yang fokus pada pemberian edukasi terkait fbAds (Gambar 7).

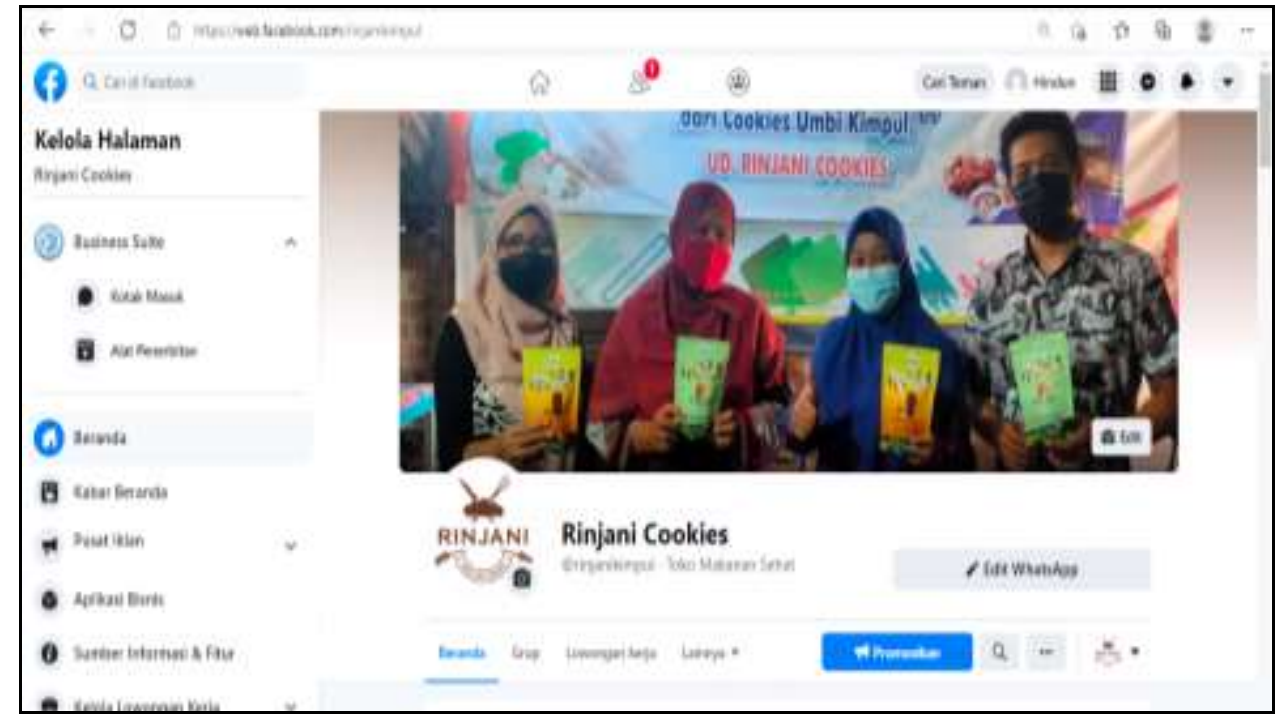

Gambar 6. Halaman facebook UD. Rinjani Cookies

Published by:

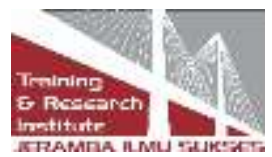




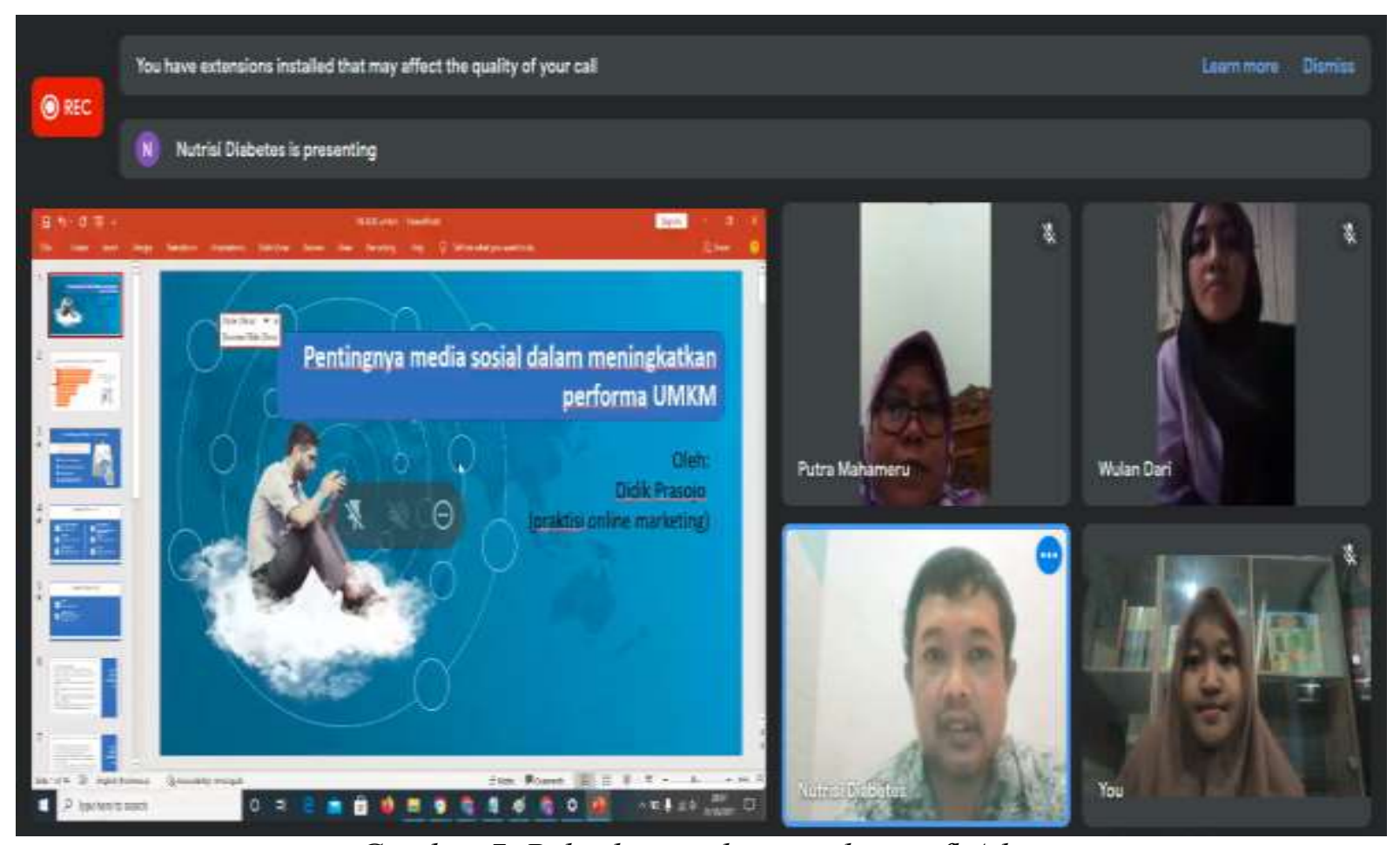

Gambar 7. Pelatihan on line marketing $f b A d s$

\subsection{Pemilihan kemasan}

Pada awal produksinya, UD. Rinjani Cookies menggunakan kemasan toples untuk mengemas produk olahannya. Kemasan toples lemah dalam daya Tarik konsumen dan selain itu kemasan toples terkesan tidak mampu menjangkau pasar yang luas. Camilan terutama kue kering yang dihasilkan oleh UD. Rinjani Cookies sangat bisa dipasarkan dalam ruang lingkup yang lebih luas, nasional bahkan internasional. Sehingga diperlukan pemilihan kemasan yang tepat untuk mendukung cita-cita tersebut. Maka dilakukan ujicoba secara mandiri menggunakan beberapa jenis kemasan antara lain toples plastic ulir, pouch plastik, pouch kombinasi plastic dan aluminium, pouch aluminium. Hasil dari ujicoba ini menunjukkan level kerenyahan dan daya tahan camilan dari urutan paling bagus adaah menggunakan kemasan aluminium, pouch kombinasi, pouch plastic dan toples. Dengan pertimbangan kerenyahan, daya tahan dan menampilkan isi produk maka dipilihlah pouch kombinasi yang kemudian dilengkapi dengan pensegelan, Gambar 8.

Published by:

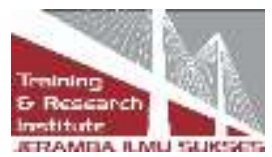




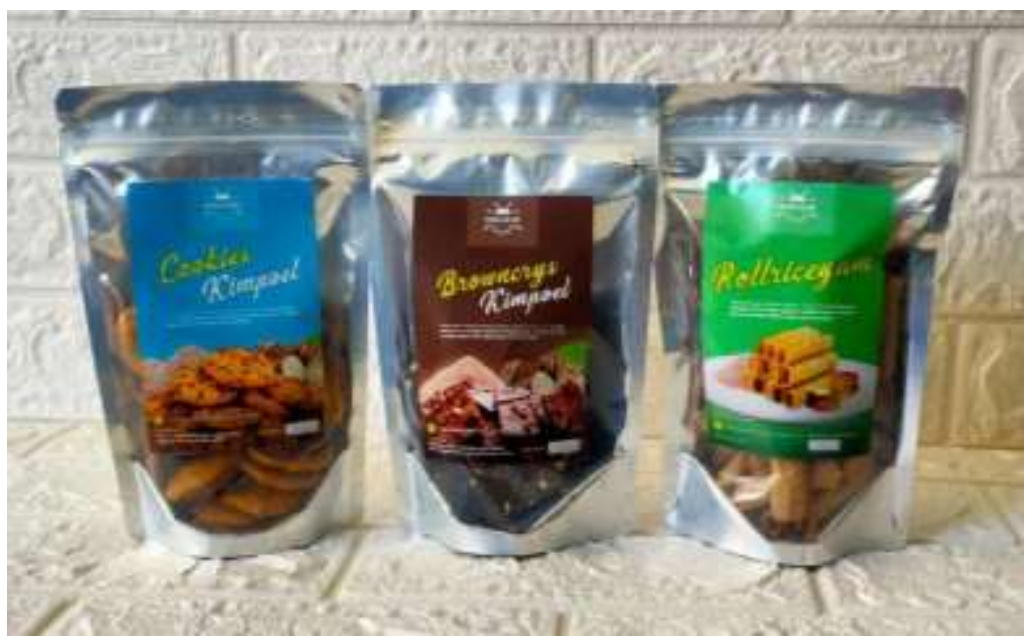

Gambar 8. Kemasan pouch kombinasi

Selain mengedukasi penggunaan kemasan, tim juga mengedukasi pentingnya melakukan pensegelan kemasan menggunakan mesin hand sealer (Gambar 9). Manfaat melakukan pensegelan kemasan antara lain mempermudah pengemasan, mengurangi tingkat kecelakaan, kemasan makanan lebih rapi, dan mengurangi kontaminasi.

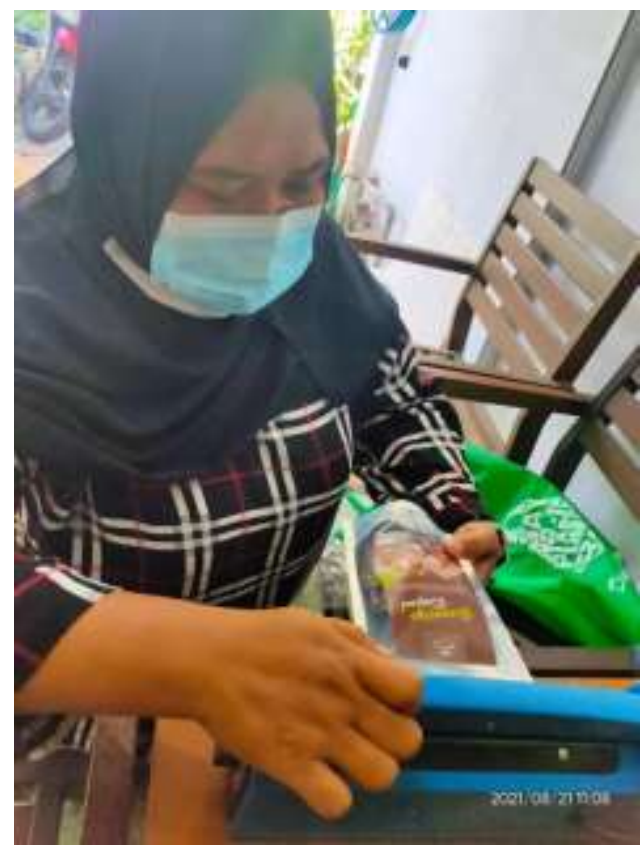

Gambar 9 Pelatihan penggunaan hand sealer.

\section{Kesimpulan}

Dengan pelaksanaan serangkaian kegiatan pengabdian masyarakat di UD. Rinjani Cookies dapat diambil kesimpulan antara lain:

Published by:

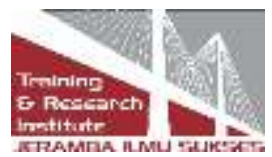


a. Pemilihan kemasan yang tepat mampu memperpanjang masa daya tahan produk.

b. Penggunaan label/kemasan yang cantik sangat membantu dalam mengikat daya Tarik konsumen.

c. Penggunaan kolaborasi media social dan marketplace bersifat simbiosis mutualisme bagi UKM dengan memanfaatkan kelebihan masing-masing tools.

\section{Acknowledgments}

Kami mengucapkan terima kasih kepada LPPM UPN "Veteran" Jawa Timur melalui skim Pengabdian Masyarakah Hibah Penerapan Hasil Penelitian Bagi Masyarakat (PIHAT) tahun 2021 kegiatan ini dapat terlaksana.

\section{Daftar Pustaka}

Hootsuite We are Social, 2020. Digital 2020 Indonesia: All The Data, Trends, And Insights You Need To Help You Understand How People Use The Internet, Mobile, Social Media, And Ecommerce. https://andi.link/hootsuite-we-are-social-indonesiandigital-report-2020/. Tanggal akses 31 Oktober 2021 13.00-14.15 WIB.

https://databoks.katadata.co.id/datapublish/2020/02/26/10-media-sosial-yang-paling-seringdigunakan-di-indonesia

Iprice insight. Peta E-Commerce Indonesia. https://iprice.co.id/insights/mapofecommerce/. Tanggal akses: 31 Oktober 2021 16.00-17.00 WIB.

Kaplan, Andreas M.; Michael Haenlein (2010) "Users of the world, unite! The challenges and opportunities of Social Media". Business Horizons 53(1): 59-68.

Media Sosial. https://id.wikipedia.org/wiki/Media_sosial. Tanggal akses: 31 Oktober 2021 20.00-20.30

\section{Copyrights}

Copyright for this article is retained by the author(s), with first publication rights granted to the journal.

This is an open-access article distributed under the terms and conditions of the Creative Commons Attribution license (http://creativecommons.org/licenses/by/4.0/) 